Article

\title{
CHARACTERIZATION OF SENSORY PERCEPTIONS ELICITED BY WHITE WINE SPIKED WITH DIFFERENT AROMA, TASTE AND MOUTH-FEEL ACTIVE MOLECULES
}

\section{CARACTERIZAÇÃO DAS PERCEPÇÕES SENSORIAIS EM VINHOS BRANCOS ADICIONADOS DE DIFERENTES MOLÉCULAS COM INFLUÊNCIA NO AROMA, SABOR E NAS SENSAÇÕES DE BOCA}

\section{Guilherme Vitorino, Mariana Mota and Manuel Malfeito-Ferreira*}

Linking Landscape Environment Agriculture and Food (LEAF) Research Center, Associated Laboratory TERRA, Instituto Superior de Agronomia, Universidade de Lisboa, Tapada da Ajuda, 1349-017 Lisboa, Portugal.

* Corresponding author: Tel.: + 351 213653448; e-mail: mmalfeito@isa.ulisboa.pt

(Received 23.07.2021. Accepted 11.10.2021)

\section{SUMMARY}

The present work was aimed at understanding the sensory responses induced by dry white wine modified with increasing concentrations of different sensory active molecules. The tasting panel was composed by 34 trained subjects characterized according to gender, smoking habits, 6-n-propylthiouracil (PROP) taster status, and sensitivity to tartaric acid, tannic acid and sucrose. Additional taste/mouthfeel responsiveness was evaluated in a basal white wine added of tartaric acid, tannic acid and sucrose. The addition of a fruity odorant mixture to the base white wine enabled the assessment of orthonasal aroma and taste intensities (sweetness, sourness, saltiness). The diversity of taste/mouthfeel responsiveness in water or wine enabled to group individuals as high or low sensitives. Likewise, the tasting panel showed two groups responding differently to aroma and flavor. Both high and low aroma sensitivity individuals showed equal (p>0.05) and congruent response to in-mouth sweet flavor perception. Moreover, the high smell sensitive group was less sensitive to sourness and saltiness than the low smell sensitives for the spiked wines across all flavor concentrations. Differences in PROP taster status and sensitivity to other tastants in water solutions were not correlated with the taste/mouthfeel perceptions in wine. The individuals most sensitive to sucrose in wine taste showed higher response to the fruity aroma. In conclusion, taste, mouthfeel and flavor perceptions showed a high variability among individuals evidencing the advantage of grouping tasters with different chemosensory sensitivities to understand cross-modal sensory interactions.

\section{RESUMO}

O presente trabalho teve como objetivo compreender as respostas sensoriais induzidas por vinho branco seco modificado com concentrações crescentes de diferentes moléculas com efeito no aroma. O painel de prova foi composto por 34 sujeitos treinados caracterizados por sexo, hábitos de tabagismo, resposta ao 6-n-propiltiouracil (PROP), sensibilidade ao ácido tartárico, ácido tânico e à sacarose. As perceções associadas ao ácido tartárico, ácido tânico e à sacarose foram também avaliadas em vinho branco. A adição de uma mistura de aromas frutados ao vinho branco base possibilitou a avaliação da intensidade de aroma ortonasal e da intensidade de sabor em relação à perceção da doçura, acidez e salgado. A diversidade de respostas aos sabores e à sensação de boca, em água e em vinho, permitiu separar os indivíduos em dois grupos com sensibilidade alta e baixa. Em conjunto, os provadores responderam de forma diferente ao aroma e ao sabor do vinho adicionado da mistura de compostos de aroma. Tanto indivíduos de alta como de baixa sensibilidade ao aroma ortonasal apresentaram uma resposta igual ( $p>0.05$ ) e congruente com a percepção de doçura na boca. Além disso, o grupo mais sensível ao cheiro era menos sensível aos sabores ácido e salgado do que os menos sensíveis ao cheiro, para os vinhos adicionados de todas as concentrações de aroma. As diferenças na resposta ao PROP e sensibilidades ao ácido tartárico, ácido tânico e à sacarose, em soluções aquosas, não foram correlacionadas com as perceções respetivas em vinho. No entanto, os indivíduos mais sensíveis à sacarose no vinho apresentaram maior resposta ao aroma frutado. Em conclusão, as perceções de sabor e sensação de boca mostraram elevada variabilidade entre os indivíduos. Desta forma, é vantajoso o agrupamento de provadores em função da sua sensibilidade quimo-sensorial para entender as interações multimodais entre os sentidos do olfato, gosto e tato, durante a prova de vinhos.

Keywords: Flavor, taste, PROP, sweetness, cross-modal, congruency.

Palavras-chave: Sabor, gosto, PROP, doce, modalidades cruzadas, congruência.

139

(C) Vitorino et al., 2021.

This is an Open Access article distributed under the terms of the Creative Commons Attribution License

(https://creativecommons.org/licenses/by/4.0), which permits unrestricted use, distribution, and reproduction in any medium, provided the original work is properly cited 


\section{INTRODUCTION}

The aroma and taste perception of wines has been deeply studied since the beginning of sensory science as an essential tool to improve wine quality (Francis and Williamson, 2015). The use of trained tasting panels besides product characterization also enabled to understand the physiological basis of individual sensitivity to the stimuli elicited by foods and beverages (Williams et al., 2016; Pickering and Hayes, 2017; Pomarici et al., 2017).

Concerning taste function, one of the most studied is the responsiveness to 6-n-propylthiouracil (PROP). The so-called PROP tasters (Medium-tasters and Super-tasters) generally perceive greater intensity than the Non-tasters from a wide variety of compounds (Prescott and Swain-Campbell, 2000; Tepper et al., 2001). The taste sensitivity may be measured using other tastants, enabling to determine overall individual orosensory responses described as hypergeusia or hypogeusia (Webb et al., 2015).

The smell sensitivities are usually measured by detection thresholds for single molecules which are highly variable among individuals and vary according to the smell pathway (ortho- or retronasal) (Bajec and Pickering, 2008; Jaeger et al., 2014; Pellegrino et al., 2021). The complexity of aromatic molecules makes difficult to use this approach to the global wine aroma. Therefore, mixtures of odorants can be used to mimic wine flavors assuming that individual differences in perception may be offset by the use of a wide variety of odorant molecules (Atanasova et al., 2004, Peng et al., 2016).

Furthermore, smell, taste and mouth-feel stimuli elicit cross-modal interactions and participate in the construction of the flavor perception (Small, 2012; Arvisenet et al., 2016). The PROP taster status has been shown to affect the perception of flavors (aromas perceived by the retronasal route) (Green and George, 2004; Pickering et al., 2006) justifying their combined study. How the perception of aroma interacts with the perception of taste has given pace to many studies addressing the concept of aroma-taste congruency. Different aroma compounds have been found to enhance wine sweetness perception, like those responsible for the fruity aroma (Sáenz-Navajas et al., 2010). Reciprocally, the addition of sweeteners has also been found to increase the perceived aroma intensity (Arvisenet et al., 2016; Bertelsen et al., 2020). The interest of studying fruity/sweetish perceptions is related to the overall consumer preference for wines marked by these features (Francis and Williamson, 2015; Malfeito-Ferreira et al., 2019).

Despite the wide body of research available on sensory perception, some issues, such as the variability of individual responsiveness to multisensory flavor stimuli pointed out by Wang et al. (2019), deserve further insight. Taste and trigeminal descriptors are more prone to cause disagreement than ortho- and retronasal aromas (Pelonnier-Magimel et al., 2020). Indeed, aromatic characterization seems to be well established, while researchers still recognize the lack of appropriate methods to deal with in-mouth attributes (taste and mouthfeel) (Arvisenet et al., 2016; Laguna et al., 2017; Gawel et al., 2018; Paissoni et al., 2018; Rinaldi and Moio, 2018), and the respective flavor cross-modal interactions (Sereni et al., 2016; Pittari et al., 2020; Sáenz-Navajas et al. ,2020).

Therefore, the overall aim of this study was to understand the factors underlying the sensitivity of the most relevant flavor active molecules in a white wine marked by fruity flavors. In the first step, several measures of taste function were determined, using water solutions and a white wine.

\section{MATERIALS AND METHODS}

\section{Taster characterisation and training}

The tasting panel was selected among students of the Vinifera Euromaster at the Instituto Superior de Agronomia (ISA) in the 2016/2017 academic year with drinking experience and able to participate in extensive training sessions. Training began by the evaluation of tastes (sweet, acid, salt, bitter), astringency and odor. The objective of these tests was to determine if the tasters were able to detect the simple tastes and the odor of the mixture. A total of 34 subjects were selected. The tastings took place in a classroom of the ISA under ambient light at $25 \pm 1$ ${ }^{\circ} \mathrm{C}$, in separated benches. The wines $(30 \mathrm{~mL})$ were poured into odor-free INAO wine glasses (ISO standard $3591: 1977)$ at $10{ }^{\circ} \mathrm{C}$, covered with Petri glasses. The tastant water solutions were served at room temperature. The sessions lasted approximately four months, from February to May 2017, performing one to three different tests each week.

Subjects were asked to complete a brief inquiry that collected basic demographic data (age, gender, smoking status, nationality, education background) and gave their written consent to participate in the study.

\section{Measurements of taste function}

\section{Scale usage}

Subjects were trained in the use of the general labeled magnitude scale (gLMS) following published standard procedures (Green et al., 1996; Bartoshuk, 2000; Pickering and Kvas, 2016). The gLMS is a psychophysical tool that requires subjects 
to rate their perceived intensity of a given stimulus along a line scale with adjectives at empirically derived intervals. The 100 points scale comprises the following adjectives: no sensation $=0$, barely detectable $=1.5$, weak $=6$, moderate $=17$, strong $=$ 35 , very strong $=52$, and the strongest imaginable sensation of any kind $=100$. The scale presented to subjects shows only the adjectives, not the corresponding numbers. The score for each measure, in $\mathrm{cm}$, was manually obtained with a ruler. Adaptation to scale usage was performed by rating several experiences that involved culturally appropriate remembered or imagined sensations, concerning pain, tastes, and senses.

\section{PROP taster status}

6-n-Propylthiouracil (PROP) taste sensitivity was assessed in duplicate during two $15 \mathrm{~min}$ sessions in two different days. Subjects rated the bitterness intensity of three PROP (Sigma, St. Louis, USA) solutions $(0.032,0.32$, and $3.2 \mathrm{mM})$ in increasing order of concentration. $20 \mathrm{~mL}$ of solution in each glass was provided to the individuals, which were instructed to move the sample inside the mouth, for 10 seconds, covering all the mouth surfaces and wait for the sensation intensity to peak (10-15 s) to spit the sample. The sensation intensity was rated by drawing a mark on the gLMS scale after 10 to $15 \mathrm{~s}$. Tasters were classified according to the bitterness rating elicited by the $0.32 \mathrm{mM}$ PROP solution using the gLMS Scale (non-taster: $\leq 15.5$; taster: $\geq 15,5$ and $<51$; super tasters $\geq 51$ ) (Prescott and Swain-Campbell, 2000). Subjects rated in a gLMS scale the saltiness intensity of three sodium chloride solutions $(\mathrm{NaCl}, 0.01,0.1$, and $1 \mathrm{mM})$ in increasing order of concentration to strengthen the PROP taster status determination. The procedure was the same as used for the PROP solutions.

Tastes and mouth-feel sensitivities in water solutions

Three solutions of tartaric acid, sucrose and tannic acid (Sigma, St. Louis, USA) were served on a randomized order $(0.1,1$ and $10 \mathrm{~g}$ of tartaric acid $/ \mathrm{L}$, $0.05,0.21$ and $0.42 \mathrm{M}$ for sucrose, $0.1,1$ and $2.5 \mathrm{~g}$ of tannic acid/L. The subjects were asked to evaluate the oral intensity of the supra-threshold solutions by using the gLMS scale, concerning sourness, sweetness and astringency, respectively. The value of the individual responsiveness to the intensity of increasing concentrations was obtained from the geometric mean of the response to each concentration, as described by Webb et al. (2015). The arithmetic average value of the mean of all responses was taken as the cut-off to classify tasters as low and high sensitivity to each tastant.

\section{Tastes and mouth-feel intensities in wine}

A base wine was used to assess taster responsiveness to acid, sweet and astringent stimuli. The base wine was an odorless Macabeo white wine produced in the 2016 at ISA experimental cellar. The wine was produced by crushing whole grapes and fermenting the free-run juice at $18-20{ }^{\circ} \mathrm{C}$ until full sugar depletion, according to standard winemaking practices. The basic analytical features were $11.3 \%$ (v/v) ethanol, $5.30 \mathrm{~g} / \mathrm{L}$ total acidity (in tartaric acid), $0.23 \mathrm{~g} / \mathrm{L}$ volatile acidity (in acetic acid), $\mathrm{pH} 3.52,39$ $\mathrm{mg} / \mathrm{L}$ free $\mathrm{SO}_{2}, 105 \mathrm{mg} / \mathrm{L}$ total $\mathrm{SO}_{2}$, and $0.7 \mathrm{~g} / \mathrm{L}$ residual sugar.

Oral intensities were determined by spiking the base wine with five solutions of tartaric acid, tannic acid and sucrose. These solutions were served in a random order of concentrations. The used concentrations were: $0.15,0.30,0.60,1.20,2.40 \mathrm{~g}$ of tartaric acid/L; 0.09, 0.19, 0.38, 0.75, 1.50 of g tannic acid/L, and 6, 12, 24, 48, 96 of $\mathrm{g}$ sucrose/L. The subjects were asked to evaluate the taste intensity of the solutions by using the gLMS scale. The value of individual response to the intensity of these increasing concentrations was obtained from the geometric mean of the response to each concentration. The arithmetic average value of the mean of all responses was taken as the cut-off to classify subjects as low and high sensitivity to each tastant. Thus, the values below the cut-off were classified as low sensitive and the values considered above were considered as high sensitive.

\section{Evaluation of wine aroma and flavor intensities}

\section{Wine and flavor addition}

The previous Macabeo base wine was flavored with increasing concentrations of an aroma mixture solution resembling the Gewürztraminer flavor. The aroma solution in ethanol was composed by several molecules with fruity and floral connotations (Table I) following the protocol described by Arvisenet et al. (2016). Three wines were prepared with increasing volumes $(0.5 \mathrm{ml} / \mathrm{L}, 1 \mathrm{ml} / \mathrm{L}$ and $2 \mathrm{ml} / \mathrm{L})$ of the aroma mixture. The solutions were added to control wine $3 \mathrm{~h}$ before the tastings.

\section{Orthonasal aroma intensity}

The global orthonasal aroma intensity was determined by measuring the distance between the nose and the glass as it is slowly approached the nose, with a $45^{\circ}$ inclination. When the taster felt the aroma, the distance from the nose to the glass was measured in $\mathrm{cm}$ with a $20 \mathrm{~cm}$ ruler. The higher the distance, the greater the aromatic intensity of the wine. The tasters rated the aroma intensity of the control wine plus the three spiked wines. The individual responsiveness was obtained by the geometric mean of the four concentrations. 


\section{Flavor intensity}

After smelling the flavored wines, assessors were asked to rate the perceived sweetness, sourness and saltiness intensities. Subjects put the sample in the mouth, rinsed for 10 seconds, being sure to cover all the in-mouth surfaces and waited for the sensation to peak ( 1 to $15 \mathrm{~s}$ ). After spiting, a mark was drawn on a general Visual Analog Scale (gVAS) using as indicators "no sensation" for the lowest/weakest scale endpoint $(0 \mathrm{~mm})$ and "strongest experienced sensation of any kind including pain" for the highest perceived endpoint $(100 \mathrm{~mm})$. The line was divided into quadrants $(25,50$, and $75 \mathrm{~mm})$ and broke up by three unlabeled mark points (Pickering and Kvas, 2016).

\section{Data Analysis}

Data obtained were subjected to variance analyses (ANOVA) $\quad(\alpha=0.05) \quad$ with software $R$ (www.r-project.org) to assess the influence of each subject category on wine taste intensity, after checking that homoscedasticity assumption was generally acceptable and violation to normality was mainly due to the unequal sample size. Factorial analysis concerning subject demographic data and taste sensitivity was performed combining more than one subject category in order to evaluate possible interaction effects. All pairwise differences between means were examined using the Tukey's test $(\alpha=0.05)$.

Table I

Aroma solution molecules and their odor properties

\begin{tabular}{|c|c|c|c|}
\hline Name & Compound & Odor description & $\begin{array}{c}\text { Concentration } \\
(\mathbf{m g} / \mathrm{L})\end{array}$ \\
\hline Isobutanol & 2-Methylpropan-1-ol & Sweet, sweaty-chemical, whiskey-like & 16.00 \\
\hline Phenethyl alcohol & 2-Phenyl ethanol & Floral, rose & 24.20 \\
\hline Isoamyl alcohol & 3-Methyl-butan-1-ol & Alcoholic, winey-brandy & 95.20 \\
\hline Ethanal & Acetaldehyde & Pungent, breathtaking & 0.94 \\
\hline Damascenone & $\beta$-damascenone & Fruity-floral with apple-plum-raisin, tea, rose, tobacco & 0.01 \\
\hline Rose-oxide & cis-Rose-oxide & Metallic, grassy-green, geranium & 0.04 \\
\hline Ethyl butanoate & Ethyl butanoate & Ether, fruity odor, buttery, ripe fruit & 0.42 \\
\hline Ethyl hexanoate & Ethyl hexanoate & Fruity, winey odor; apple, banana, pineapple & 1.02 \\
\hline Ethyl octanoate & Ethyl octanoate & Fruity, winey, sweet odor, cognac-apricot & 1.02 \\
\hline Isoamyl acetate & Isoamyl acetate & Sweet, fruity, banana, pear & 2.54 \\
\hline Linalool & Linalool & Floral-woody odor with faint citrus note, sweet floral & 0.36 \\
\hline
\end{tabular}

\section{RESULTS AND DISCUSSION}

\section{Taster Characterization}

\section{Demographic inquiries}

The tasting panel was composed of 21 females and 13 males with an average age of $24.6 \pm 5.2$ years old. The age range was from 19 to 40 years old. Given the relatively low age variation, the factor age was not taken into account in the sensory evaluations. The subjects did not report food allergies and vegetarianism. The smoking habits revealed 12 smokers; three reported occasional smokers were included in the non-smokers group (22 individuals).

\section{Measures of taste function}

\section{PROP taster status}

Concerning taste sensitivity, the mean responses of each category to PROP bitterness and $\mathrm{NaCl}$ taste intensity are presented in Figure 1. The relationship between $\mathrm{PROP}$ and $\mathrm{NaCl}$ showed the expected trend mentioned by Tepper et al. (2001). In this study, there were 12 Non-Tasters (NT), 20 Medium-Tasters (MT) and 2 Super-Tasters (ST). Considering the low number of ST, this group was merged with the MT group when ANOVA was performed. Therefore, about $65 \%$ of the tasters were sensitive to bitterness, which roughly corresponded to an average of $75-80 \%$ in a Caucasian population (Tepper, 2008; Robino et al., 2022), and was lower than the percentage of $80-90 \%$ for Asian individuals (Guo and Reed, 2001). Recently, several reports associated bitterness sensitivity with other biological effects beyond food habits such as longevity (Melis et al., 2019) and cancer susceptibility (Singh et al., 2020). Given that wine has also been related to disease prevention (Santos-Buelga et al., 2021), it would be interesting to associate wine with this topic in future research. 
Tastes and tactile sensations

The perceived intensities elicited by tartaric acid, tannic acid and sucrose in water solutions were examined using a gLMS scale as in the PROP evaluations. The geometric mean of each taster response across the three concentrations of each molecule provided a measure of the individual sensitivity, which allowed for systematizing the distribution of these responses. The distribution of the mean intensities is shown in Figure 2

The panel was divided into high and low sensitivities to the tastants and astringency taking the average of the geometric mean as the cut-off value. The response to each stimulus by high and low sensitive individuals is shown in Figure 3.

It would be interesting to assess whether any relationship between the different taste responses showing high responsiveness to all tastes existed, as suggested by Webb et al. (2015). In fact, most of the tasters showed a diverse pattern of sensitivities to PROP and to the other three tastants. Indeed, PROP Super-Tasters were Low responsive to tannic acid, and only three PROP Non-Tasters were Low responsive to the other three tastants (Table II).

Taste and mouth-feel intensities in white wine

The oral intensity of molecules added to white wine induced increasing responsiveness and showed high variability in the responses (results not shown). Measure of individual sensitivity was obtained by calculating the geometric mean of the scores across all tastant concentrations. Then, the panel was separated into high and low sensitivities, using as cut-off value the average of the geometric means of the responses as described by Webb et al. (2015) (Figure 4).
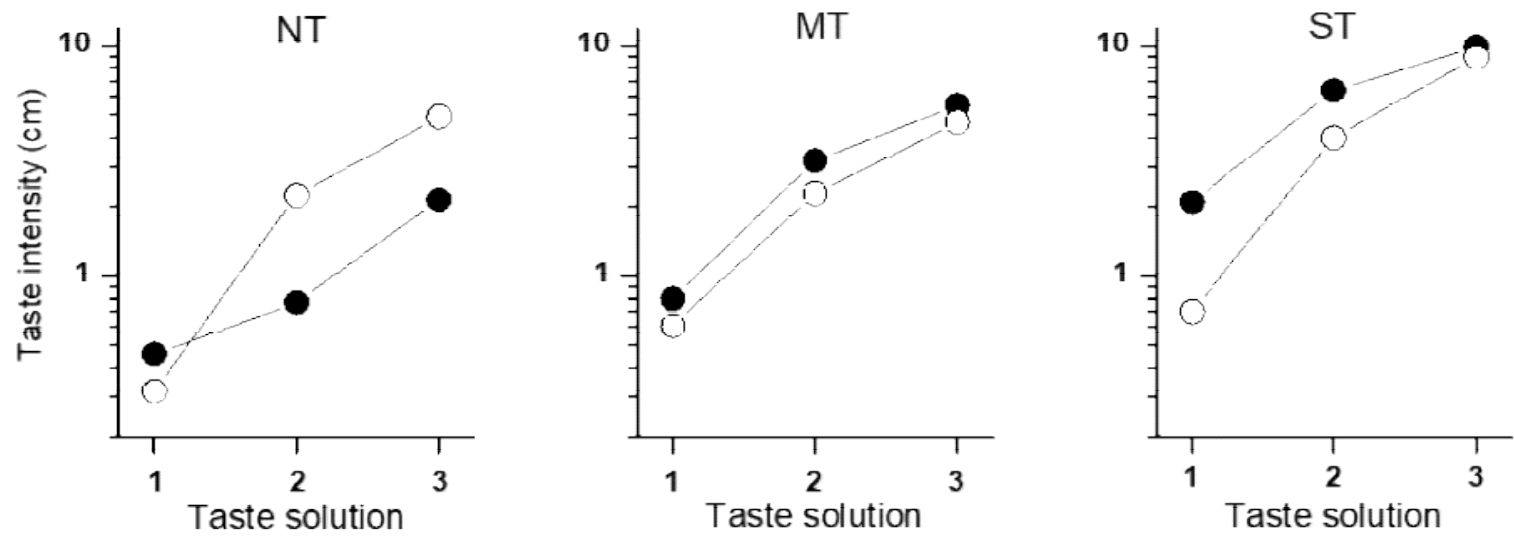

Figure 1. Taste intensities elicited by PROP $(\bullet)(1,0.032 \mathrm{mM} ; 2,0.32 \mathrm{mM} ; 3,3.2 \mathrm{mM})$ and $\mathrm{NaCl}(0)$ solutions $(1,0.01 \mathrm{M} ; 2,0.1 \mathrm{M} ; 3,1 \mathrm{M})$ according to each PROP taster status (NT, Non-tasters; MT, Medium-tasters; ST, Super-tasters).
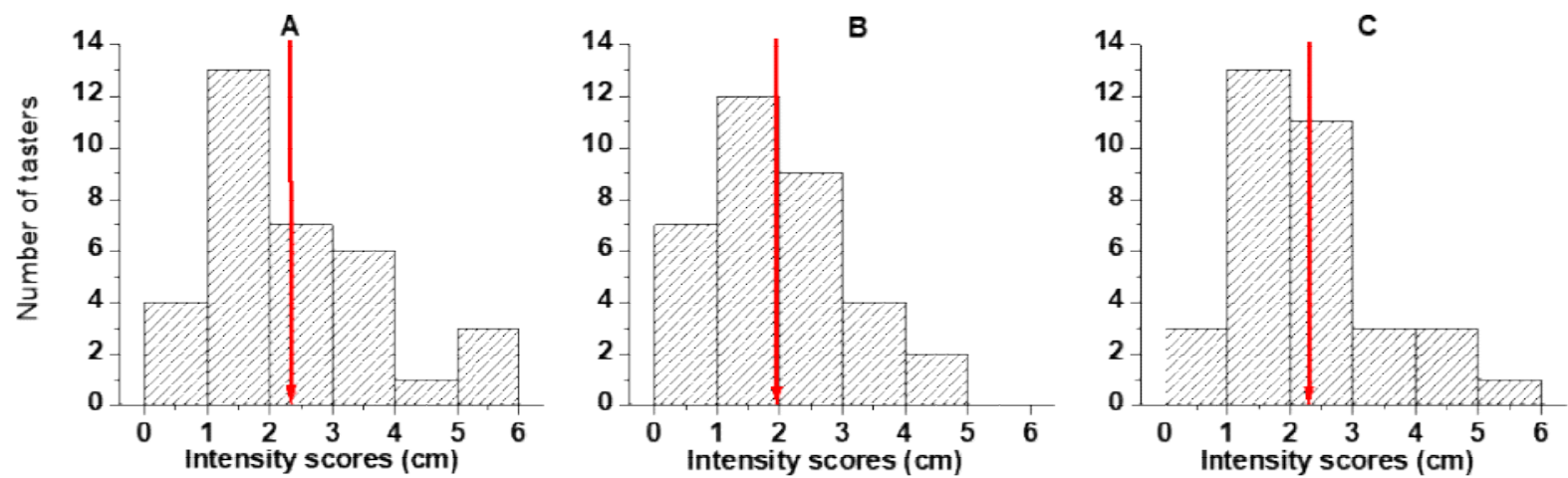

Figure 2. Histograms of individual mean intensity responses to tartaric acid (A), tannic acid (B) and sucrose (C) in water solutions. Vertical red arrows indicate cut-off values to separate between high and low sensitive individuals. 

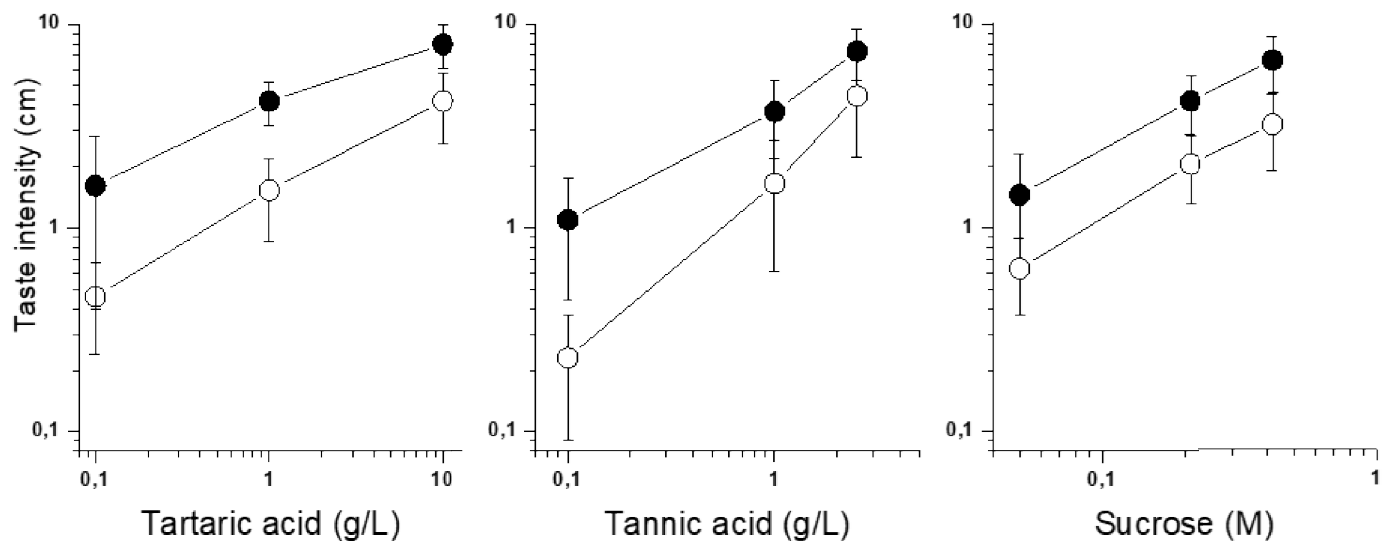

Figure 3. Intensity scores of tartaric acid, tannic acid and sucrose in water solutions for high $(\bullet)$ and low (०) intensity categories. The means values for each concentration for high and low sensitive tasters were significantly different $(\mathrm{p}<0.05)$.

Table II

Taster grouping according to PROP taster status and respective sensitivity to taste and astringent stimuli in water (ST, Super-taster; MT, Medium-taster; NT, non-taster; H, High responsiveness; L, Low responsiveness)

\begin{tabular}{clccc}
\hline \multirow{2}{*}{ PROP taster status } & \multirow{2}{*}{ Tasters } & & Sensitivity group & \\
\cline { 3 - 5 } & & Tartaric acid & Tannic Acid & Sucrose \\
\hline ST & 16 & $\mathrm{H}$ & $\mathrm{L}$ & $\mathrm{H}$ \\
& 32 & $\mathrm{H}$ & $\mathrm{L}$ & $\mathrm{L}$ \\
& $5,6,7$ & $\mathrm{H}$ & $\mathrm{H}$ & $\mathrm{H}$ \\
& 11 & $\mathrm{H}$ & $\mathrm{H}$ & $\mathrm{L}$ \\
& 25 & $\mathrm{H}$ & $\mathrm{L}$ & $\mathrm{H}$ \\
& $14,18,21,22,30$ & $\mathrm{H}$ & $\mathrm{L}$ & $\mathrm{L}$ \\
& $2,8,15$ & $\mathrm{~L}$ & $\mathrm{H}$ & $\mathrm{H}$ \\
& $10,13,17,28$ & $\mathrm{H}$ & $\mathrm{H}$ & $\mathrm{L}$ \\
& $19,23,29$ & $\mathrm{~L}$ & $\mathrm{~L}$ & $\mathrm{H}$ \\
& 1 & $\mathrm{H}$ & $\mathrm{H}$ & $\mathrm{H}$ \\
& 26 & $\mathrm{H}$ & $\mathrm{L}$ & $\mathrm{H}$ \\
& 20 & $\mathrm{H}$ & $\mathrm{H}$ & $\mathrm{L}$ \\
& 3,4 & $\mathrm{~L}$ & $\mathrm{H}$ & $\mathrm{H}$ \\
& 12,27 & $\mathrm{~L}$ & $\mathrm{~L}$ & $\mathrm{H}$ \\
& 9,24 & $\mathrm{~L}$ & $\mathrm{~L}$ & $\mathrm{~L}$ \\
\hline
\end{tabular}

The response of high and low sensitive groups is shown in Figure 5. For all molecules, the tasting panel yielded different sensitivities between the first and last tested concentration $(p<0.05)$, demonstrating the increasing perceived taste intensity.

The oral response of each individual according to PROP taster status is presented in Table III, showing a diverse pattern of responses. The sensitivity to PROP was not correlated ( $\mathrm{r}$ values less than 0.2 ) with the sensitivity to tartaric acid, tannic acid and sucrose in white wine (results not shown). Only two tasters showed a low response to all stimuli while none of the PROP super-tasters were highly sensitive to the other three tastants. In addition, the previously reported (Figure 3) responsiveness to these tastants in water solutions (tartaric acid, tannic acid, sucrose) was also not correlated ( $\mathrm{r}$ values less than 0.1 ) with the mean intensity scores given to the same stimuli in wine (results not shown). On the contrary, the correlations among stimuli in white wine were moderate ( $\mathrm{r}$ values raging from 0.36 to 0.50 ) as shown in Figure 6.

Webb et al. (2015), comparing several measures of taste function, concluded that there are multiple perceptual phases of taste with no single measure able to capture the totality of the sense of taste. The obtained results concur with these observations, showing low or moderate correlations between the sensitivity to supra-threshold concentrations of tartaric acid, sucrose, tannic acid and PROP bitterness. Increased or diminished taste response to multiple stimuli has been named as hypergeusia or hypogeusia, respectively, by Hayes and Keast (2011). These authors claimed that this definition is more precise than that of PROP taster status because it concerns responses to more than one stimulus. The most common behavior found in this study was a 
diversity of responses among the different tastants, highlighting the rarity of both hyper- or hypogeusia among the subjects.

\section{Aroma and flavor intensities in white wine}

After performing the previous in-mouth sensitivity tests, the tasting panel assessed the aroma and flavor intensities (sweetness, sourness and saltiness) elicited by the base white wine spiked with increasing levels of an odorant mixture mimicking fruity and floral notes. The results for all tasters are shown in Figure 7, illustrating a high variability of individual responses. Nevertheless, the average intensity scores showed a significant increase $(p<0.05)$ between the first and the last odorant mixture concerning aroma and sweetness perceptions, while sourness and saltiness were constant across all concentrations. Thus, there was a congruent response between increasing orthonasal aroma and sweetness perception.

The individual values of intensity scores for each odorant mixture concentration were geometrically averaged, and this value was taken as the individual sensitivity score, due to the observed variability. The distribution of the geometric means of these individual scores for the several flavors and aroma is shown in Figure 8. The average of the geometric means was $3.0 \mathrm{~cm}$ (sweetness), $5.0 \mathrm{~cm}$ (sourness), $4.0 \mathrm{~cm}$ (saltiness) and $9.04 \mathrm{~cm}$ (aroma), which were used as the cut-off values between classes of high and low sensitivity tasters. The intensity responses to increasing odorant concentrations according to each sensitivity class are shown in Figure 9.
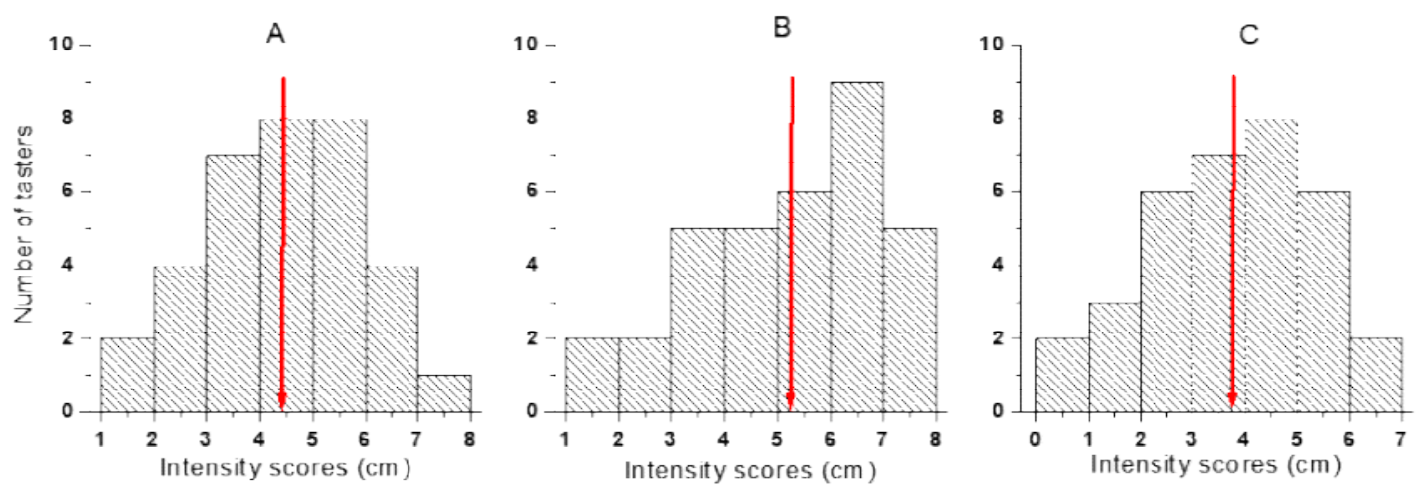

Figure 4. Histograms of individual mean intensity responses to tartaric acid (A), tannic acid (B) and sucrose (B) in white wine. Vertical red arrows indicate cut-off values to separate between high and low sensitive individuals.

Table III

Taster grouping according to PROP taster status and respective sensitivity to taste and astringent stimuli in white wine (ST, Super-taster; MT, Medium-taster; NT, Non-taster; H, High responsiveness; L, Low responsiveness).

\begin{tabular}{clccc}
\hline \multirow{2}{*}{ PROP taster status } & Tasters & \multicolumn{3}{c}{ Sensitivity group } \\
\cline { 3 - 5 } & & Tartaric acid & Tannic Acid & Sucrose \\
\hline ST & 16 & $\mathrm{H}$ & $\mathrm{H}$ & $\mathrm{L}$ \\
& 32 & $\mathrm{~L}$ & $\mathrm{~L}$ & $\mathrm{H}$ \\
& $15,17,18,21,30$ & $\mathrm{H}$ & $\mathrm{H}$ & $\mathrm{H}$ \\
& 10 & $\mathrm{H}$ & $\mathrm{H}$ & $\mathrm{H}$ \\
& $5,14,28$ & $\mathrm{H}$ & $\mathrm{L}$ & $\mathrm{H}$ \\
& 11 & $\mathrm{H}$ & $\mathrm{L}$ & $\mathrm{L}$ \\
& 22,23 & $\mathrm{~L}$ & $\mathrm{H}$ & $\mathrm{H}$ \\
& 6,7 & $\mathrm{~L}$ & $\mathrm{H}$ & $\mathrm{L}$ \\
& 25 & $\mathrm{~L}$ & $\mathrm{~L}$ & $\mathrm{H}$ \\
& $2,8,13,19,29$ & $\mathrm{H}$ & $\mathrm{H}$ & $\mathrm{L}$ \\
& 3,31 & $\mathrm{H}$ & $\mathrm{L}$ & $\mathrm{L}$ \\
& 12,20 & $\mathrm{H}$ & $\mathrm{H}$ & $\mathrm{H}$ \\
& 34 & $\mathrm{~L}$ & $\mathrm{H}$ & $\mathrm{L}$ \\
& $1,9,24$ & $\mathrm{~L}$ & $\mathrm{H}$ & $\mathrm{L}$ \\
\hline
\end{tabular}



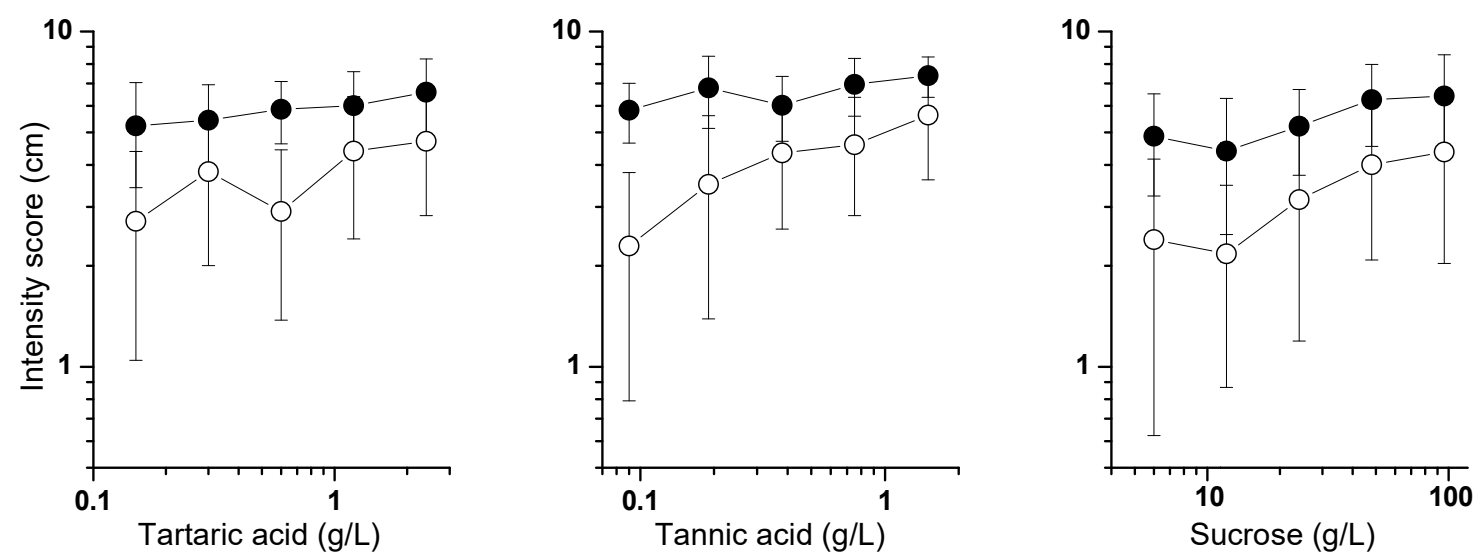

Figure 5. Intensity scores of tartaric acid, tannic acid and sucrose in white wine for high $(\bullet)$ and low $(\circ)$ intensity categories. The means values for each concentration for high and low sensitive tasters were significantly different $(\mathrm{p}<0.05)$.
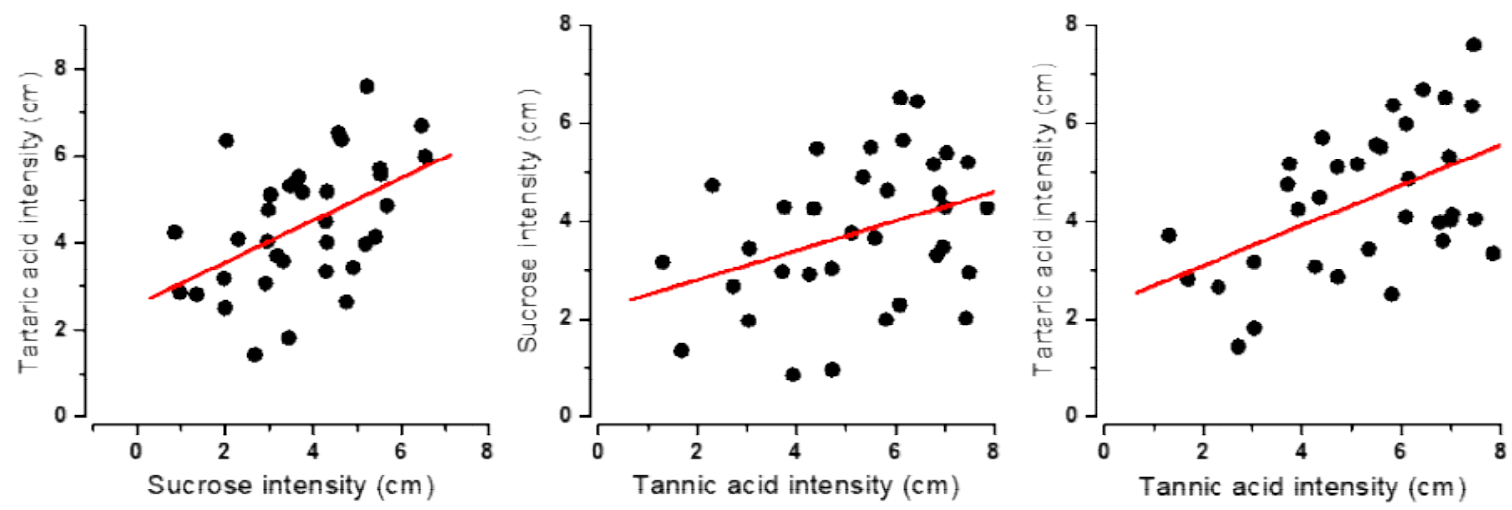

Figure 6. Relations between responsiveness among tastes and mouth-feel sensation in white wine. Each dot represents the geometric mean of responses across the tested concentrations of each stimuli. Correlation coefficients (r): 0.49 , tartaric acid x sucrose; 0.36 , sucrose $\mathrm{x}$ tannic acid; 0.50 , tartaric acid $\mathrm{x}$ tannic acid.
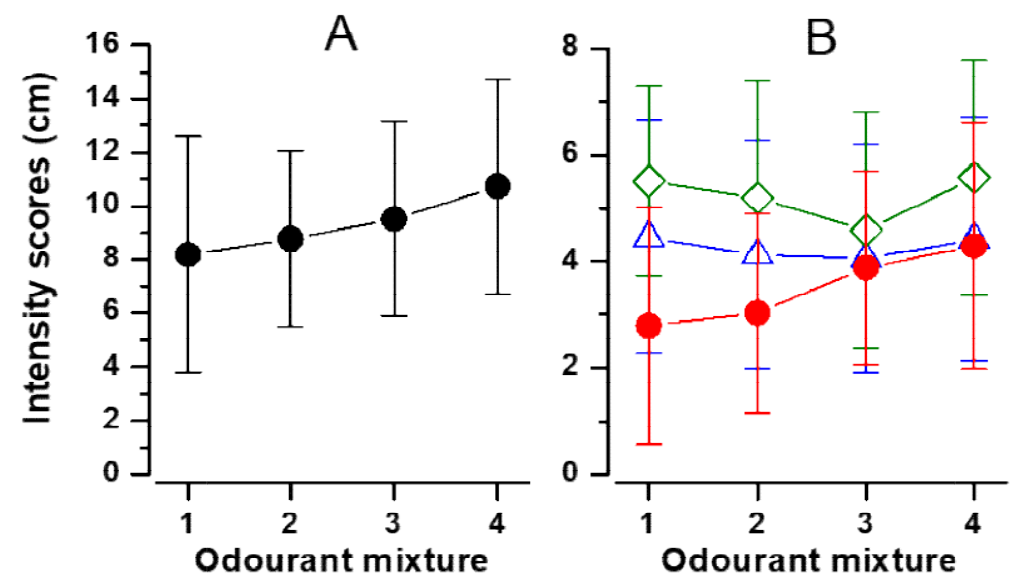

Figure 7. Intensity scores of orthonasal aroma (A) and retronasal flavors (B) in white wine spiked with increasing odorant concentrations. Perceptions: •, aroma; $\bullet$, sweetness; $\diamond$, sourness; $\Delta$, saltiness). 

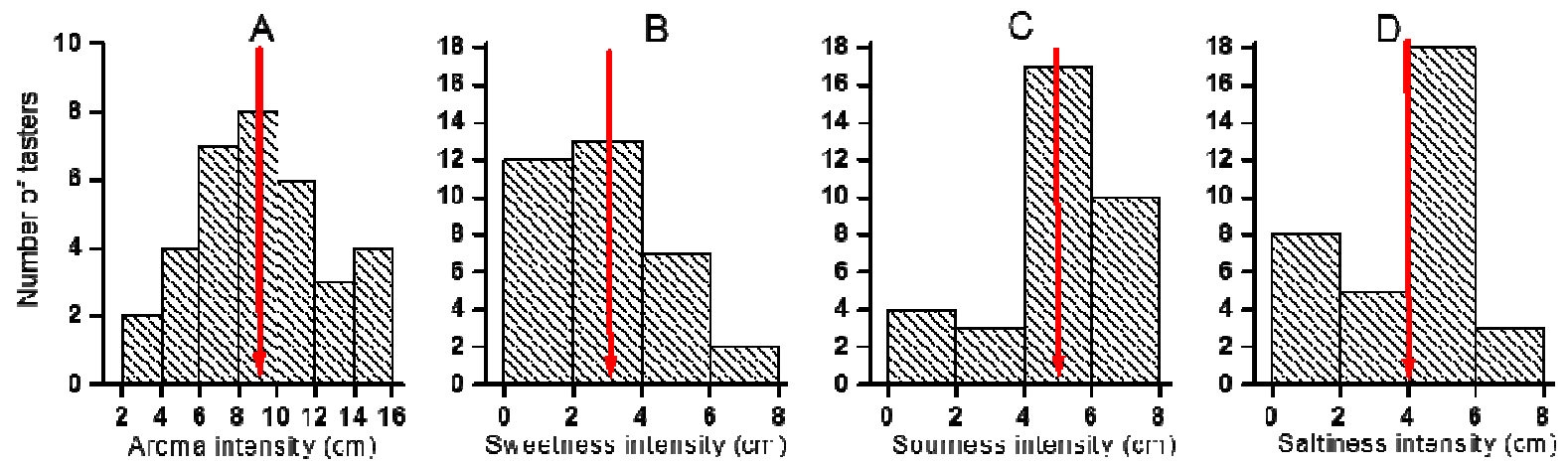

Figure 8. Histograms of individual mean intensity responses elicited by white wine spiked with increasing odorant concentrations. Vertical red arrows indicate cut-off values to separate between high and low sensitive individuals (A, aroma; B, Sweetness; C, Sourness; D, Saltiness).
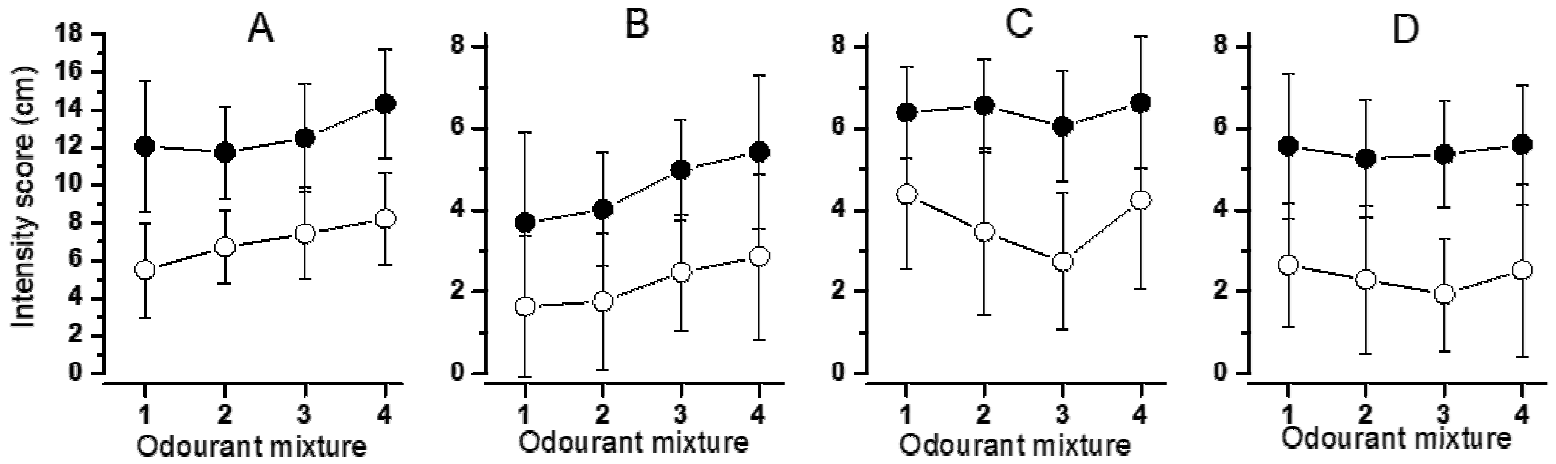

Figure 9. Intensity scores elicited by increasing odorant concentrations spiked in white wine for high (•) and low (०) intensity categories

(A, Aroma; B, Sweetness; C, Sourness; D, Saltiness). The average scores for each odorant concentration were significantly different $(\mathrm{p}<0.05)$ for all sensations.

The obtained results also evidence the influence of the tasting media on the observation of taste relationships. The relationships between PROP sensitivity and water solutions of other tastants was moderate but it was absent $(\mathrm{r}<0.2)$ when compared to the intensities elicited by tastants diluted in wine. This result conflicts with the higher orosensory sensitivity by PROP tasters reported in red wine (Pickering et al., 2004; Pickering and Robert, 2006). The use of different matrices may explain this different outcome, showing that generalizations of PROP taster status as a predictor of individual taste sensitivities in wines are not appropriate.

The determination of individual responses to orthonasal aroma intensity is commonly used in sensory analysis using olfactometers (Diaz, 2004) but there is no obvious method to determine it in wine. Tasting manuals only mention smelling wine in standardized glasses but with no specific methodology (Jackson, 2002). Sáenz-Navajas et al. (2010) did not obtain consistent assessments of aromatic intensity and, therefore, did not use this parameter in their study, which may be surprising considering the participation of highly trained individuals. Probably, the existence of different aroma sensitivities, as shown in this work, explains the outcomes reported by Sáenz-Navajas et al. (2010).

\section{Influence of taster categories on aroma and flavor perceptions}

The previous aroma and flavor sensitivity results were obtained for all tasters and it would be interesting to check if the different demographic and taste function categories would yield different responses to the white wine spiked with increasing odorant concentrations. For this purpose, an ANOVA was carried out considering the different demographic (Gender, Smoker), taste function (PROP taster status, tartaric acid sensitivity, tannic acid sensitivity and sucrose sensitivity), and the categories elicited by tastants added to white wine (tartaric acid, tannic acid, sucrose) as factors. The predictors were the scores given to aroma and taste intensities. Interestingly, the correlations were only observed with taste sensitivities in wine (Table IV), namely: (i) tasters more sensitive to sucrose in water solution yielded higher aroma intensities; (ii) tasters more sensitive to tannic acid yielded higher perception of sweetness. 
Therefore, the aroma sensitivity could not be predicted from the sensitivity to water solutions of tartaric acid, sucrose or tannic acid. Despite reported differences in gender taste responsiveness (Williams et al., 2016), neither smell or taste sensitivities were found. The effects of smoking habits on taste or flavor are controversial (Nettore et al., 2020). These authors, with a cohort of 83 smokers among 348 subjects, reported that flavor recognition was not affected by cigarette smoking. The results of the present study, although with a smaller population, concur with these observations.

When an ANOVA was performed taking into consideration the aroma sensitivity as variable, the results showed that high and low aroma sensitive tasters yielded similar sweetness perceptions (Table V). Therefore, the higher perception of the spiked fruity flavors through the orthonasal route (aroma) was not accompanied by an equivalent increase in the perception of sweetness through the retronasal pathway. On the contrary, the low aroma sensitive tasters yielded higher scores for sourness and sweetness (Table V).

The different individual sensitivities to aroma and flavor provided additional evidence for the complexity of the multisensory studies. Overall, the results presented reinforce the statement of Parr (2019) who explained that sensitivity variation is not an "error in the machine". Thus, the conventional training of tasting panels expected to minimize physiological and psychological biases (Lesschaeve, 2007; Pinto, 2021) should consider the different individual responses, contrarily to the usual practices when studying aroma-taste cross-modal interactions, as reviewed by Wang et al. (2019).

Hort and Hollowood (2004) reported that a subgroup of trained assessors was unaffected by cross-modal aroma-sweetness interactions while evaluating the intensity of fruity flavor. Moreover, Arvisenet et al. (2019) reported that trained panelists are not fully able to distinguish congruent and simultaneous flavor and aroma perceptions. This observation may be the reason for the moderate correlation $(\mathrm{r}=0.42)$ between 'Overall flavor' intensity and 'overall aroma' intensity found by Jones et al. (2008). This difference between flavour and aroma sensitivity is in accordance with the different neuronal integration of both olfaction pathways (Small, 2012). Both studies may also suffer from an analytical bias known as "dumping effect" due to similarity in the fruity smell and sweet taste (Poinot et al., 2013). The "dumping effect" should have been minimized in the present work due to the use of different intensity scales for aroma and flavor Thus, the present work provides further evidence for the differences in individual sensitivity related with the ortho- or retronasal pathways (Pellegrino et al., 2021) and strengthens the need to take this different response into account when studying the multisensory integration of percepts.

Table IV

Effect of sensitivity categories to sucrose and tannic acid in wine on aroma and sweetness intensities of wine spiked with increasing flavor concentrations

\begin{tabular}{lllccc}
\hline Perception & Categories & Class & P-values & Mean \pm sd & Subjects \\
\hline Aroma Intensity & Sucrose & High & 0.049 & $10.09^{\mathrm{a}} \pm 3.35$ & 14 \\
& & Low & & $8.75^{\mathrm{b}} \pm 4.21$ & 20 \\
\multirow{2}{*}{ Sweetness Intensity } & Tannic Acid & High & 0.003 & $4.04^{\mathrm{a}} \pm 1.99$ & 16 \\
& & Low & & $2.98^{\mathrm{b}} \pm 2.14$ & 18 \\
\hline
\end{tabular}

${ }^{a, b}$ Mean values in the same column followed by different letters are significantly different $(\mathrm{p}<0.05)$.

Table V

Aroma and flavour sensitivities given by high and low aroma sensitive tasters to white wines spiked with increasing aroma concentrations

\begin{tabular}{llcc}
\hline \multirow{2}{*}{ Categories } & p-value & High aroma sensitive tasters & Low aroma sensitive tasters \\
\cline { 3 - 4 } & & Mean \pm sd & Mean \pm sd \\
\hline Aroma Intensity & $2.00 \mathrm{E}-16$ & $12.66^{\mathrm{a}} \pm 3.04$ & $6.96^{\mathrm{b}} \pm 2.51$ \\
Sweetness Intensity & 0.232 & $3.23^{\mathrm{a}} \pm 2.03$ & $3.68^{\mathrm{a}} \pm 2.20$ \\
Sourness Intensity & $5.02 \mathrm{E}-05$ & $4.35^{\mathrm{a}} \pm 2.43$ & $5.82^{\mathrm{b}} \pm 1.66$ \\
Saltiness Intensity & 0.00642 & $3.66^{\mathrm{a}} \pm 2.19$ & $4.69^{\mathrm{b}} \pm 2.07$ \\
\hline
\end{tabular}

${ }^{a, b}$ Mean values in the same row followed by different letters are significantly different $(\mathrm{p}<0.05)$. 
One of the challenges to study cross-modal interactions is to use methods that may be as close to real food and drink matrices as possible (Parr, 2019). The approach used in this work showed that the increase in sweetness perception (retronasal pathway) in dry white wine was induced by an increasing concentration of fruity/flowery odorant molecules. This result suggests that the congruent response between the floral/fruity flavor ("sweet" flavor) and the perception of sweetness develops (Wang et al., 2019) while maintaining the sourness sensitivity. Contrarily, Jones et al. (2008), using water solutions, found that acidity, and not sweetness, was affected by increasing flavor concentration.

\section{Limitations of the study}

One of the limitations of this study was the relatively small tasting panel size and diversity. The training demanded for time and availability that was achieved at the cost of a lesser number of subjects. After taster categorization, several classes remained with few respondents, albeit higher than the standard requirement for trained individuals, justifying further experiments with larger tasting panels.

The research related to the effect of flavor or taste on wine sensory features is most frequently based on synthetic or reconstituted wine to better standardize the matrix under evaluation (Wang et al., 2019; Poinot et al., 2013). However, wine complexity is not fully captured by these approaches. Therefore, a real white wine with realistic fruity aroma concentrations seemed to be more meaningful to the purpose of the present study. In future work aroma-taste interactions may be studied using mixtures with other aromatic vectors (e. g. vegetal, oak) and base wines with different mouth-feel attributes (e.g. astringent white wines with maceration).

\section{CONCLUSIONS}

The results presented showed the individual variation in aroma and taste sensitivities. Using wines spiked with increasing aroma concentration proved to be a valid approach to study cross-modal interactions between smell and taste. Regarding orthonasal aroma, the results showed that tasters can be separated into high and low sensitives with different perception of sourness and saltiness but with similar sweet taste sensitivities. Hence, the in-mouth sweetness perception can be regarded as a flavor percept congruent with the increasing concentration of fruity aromatic molecules detected by the smell orthonasal pathway.

\section{ACKNOWLEDGEMENTS}

This research was funded by national funds of the FCT (Fundação para a Ciência e a Tecnologia, I.P.) under the frame of the research unit UID/AGR/04129/2020 (LEAF).

CONFLICTS OF INTEREST: The authors declare no conflict of interest.

\section{REFERENCES}

Arvisenet G., Ballester J., Ayed C., Sémon E., Andrio, I., Le Quere J-L., Guichard E., 2019. Effect of sugar and acid composition, aroma release and assessment conditions on aroma enhancement by taste in model wines. Food Qual. Pref., 71, 172-180.

Arvisenet G., Guichard E., Ballester J., 2016. Taste-aroma interaction in model wines: Effect of training and expertise. Food Qual. Pref., 52, 211-221.

Atanasova B., Thomas-Danguin T., Langlois D., Nicklaus S., Etievant P., 2004. Perceptual interactions between fruity and woody notes of wine. Flavor Fragr. J., 19, 476-482.

Bajec M.R., Pickering G.J., 2008. Thermal taste, PROP responsiveness, and perception of oral sensations. Physiol. Behav., 95, 581-590.

Bartoshuk L.M., 2000. Comparing sensory experiences across individuals: recent psychophysical advances illuminate genetic variation in taste perception. Chem. Senses, 25,448-456.

Bertelsen A., Mielby L., Alexi N., Byrne D., Kidmose U., 2020. Sweetness Enhancement by Aromas: Measured by Descriptive Sensory Analysis and Relative to Reference Scaling. Chem. Senses, 45, 293-301.

Diaz M., 2004. Comparison between orthonasal and retronasal flavor perception at different concentrations. Flavour. Frag. J., 19, 499-504.

Francis I.L., Williamson P.O., 2015. Application of consumer sensory science in wine research. Austr. J. Grape Wine Res., 21, 554-567.

Gawel R., Smith P.A., Cicerale S., Keast R., 2018. The mouthfeel of white wine. Crit. Rev. Food Sci. Nutr., 58, 2939-2956.

Green B.G., Dalton P., Cowart B., Shaffer G., Rankin K., Higgins J., 1996. Evaluating the 'Labeled Magnitude Scale' for measuring sensations of taste and smell. Chem. Senses, 21, 323-334.

Green B.G., George P., 2004. 'Thermal taste' predicts higher responsiveness to chemical taste and flavor. Chem. Senses, 29, 617-28.

Guo S., Reed D., 2001. The genetics of phenylthiocarbamide perception. Ann. Human Biol., 28, 111-142.

Hayes J.E., Keast R., 2011. Two decades of supertasting: Where do we stand? Physiol. Behav., 104, 1072-1074.

Hort J., Hollowood T.A., 2004. Controlled continuous flow delivery system for investigating taste-aroma interactions. $J$. Agric. Food Chem., 52, 4834-4843.

ISO standard 3591:1977. Sensory analysis - Apparatus Wine-tasting glass. 3 p. International Organization for Standardization, Geneva, Switzerland. 
Jackson R.S., 2002. Wine Tasting: A Professional Handbook (2nd ed). 519 pp. Academic Press, London, UK.

Jaeger S., Silva H., Lawless H., 2014. Detection thresholds of 10 odor-active compounds naturally occurring in food used a replicated forced-choice ascending methods of limits. J. Sens. Stud., 29, 43-55.

Jones P., Gawel R., Francis I., Waters E., 2008. The influence of interactions between major white wine components on the aroma, flavorant texture of model white wine. Food Qual. Pref., 19, 596-607.

Laguna L., Bartolomé B., Moreno-Arribas M.V., 2017. Mouthfeel perception of wine: Oral physiology, components and instrumental characterization. Trend. Food Sci. Technol., 59, 49-59.

Lesschaeve, I., 2007. Sensory evaluation of wine and commercial realities: review of current practices and perspectives. Am. J. Enol. Vitic., 58, 252-258.

Malfeito-Ferreira M., Diako C., Ross C., 2019. Sensory and chemical characteristics of 'dry' wines awarded gold medals in an international wine competition. J. Wine Res., 30, 204-219.

Melis M., Errigo A., Crnjar R., Pes G.M., Tomassini-Barbarossa I., 2019. TAS2R38 bitter taste receptor and attainment of exceptional longevity. Sci. Reports, 9, 18047.

Nettore I. C., Maione L., Desiderio S., De Nisco E., Franchini F., Palatucci G., Ungaro P., Cantone E., Macchia P. E., Colao A., 2020. Influences of Age, Sex and Smoking Habit on Flavor Recognition in Healthy Population. Int. J. Environ. Res. Public Health, 17, 959

Paissoni M., Waffo-Teguo P., Ma W., Jourdes M., Rolle L., Teissedre P.-L., 2018. Chemical and sensorial investigation of in-mouth sensory properties of grape anthocyanins. Scientific Reports, 8, 17098.

Parr W., 2019. Demystifying wine tasting: Cognitive psychology's contribution. Food Res. Int., 124, 230-233.

Pellegrino R., Hörberg T., Olofsson J., Luckett C., 2021. Duality of Smell: Route-Dependent Effects on Olfactory Perception and Language. Chem. Senses, 46, bjab025.

Pelonnier-Magimel E., Windholtz S., Masneuf-Pomarède I., Barbe J.-C., 2020. Sensory characterisation of wines without added sulfites via specific and adapted sensory profile. $O E N O$ One, 54, 671-685.

Peng M., Hautus M., Jaeger S., 2016. Methods for Fitting Olfactory Psychometric Functions: A Case Study Comparing Psychometric Functions for Individuals with a "Sensitive" or "Insensitive" Genotype for $\beta$-Ionone. Chem. Senses, 41, $771-782$.

Pickering G.J., Kvas R., 2016. Thermal Tasting and Difference Thresholds for Prototypical Tastes in Wine Chemos. Percept., 9, 37-46.

Pickering G.J., Haverstock G., DiBattista D., 2006. Evidence that sensitivity to 6-n-propylthiouracil (PROP) affects perception of retro-nasal aroma intensity. J. Food Agric. Environ., 4, 15-22.

Pickering G.J., Hayes J., 2017. Influence of biological, experiential and psychological factors in wine preference segmentation. Austr. J. Grape Wine Res., 23, 154-161.

Pickering G.J., Robert G., 2006. Perception of mouthfeel sensations elicited by red wine are associated with sensitivity to 6-N-propylthiouracil. J. Sens. Stud., 21, 249-265.

Pickering G.J., Simunkova K., DiBattista D., 2004. Intensity of taste and astringency sensations elicited by red wines is associated with sensitivity to PROP (6-n-propylthiouracil). Food Qual. Pref., 15, 147-154.
Pinto M., 2021. Evaluating uncertainty in sensory analysis. A case study of the panel of tasters of the Dão Regional Wine Commission. Ciência Téc. Vitiv., 36, 22-31.

Pittari E., Moio L., Arapitsas P., Curioni A., Gerbi V., Parpinello G.P., Ugliano M., Piombino P., 2020. Exploring olfactory-Oral cross-modal interactions through sensory and chemical characteristics of italian red wines. Foods, 9, 1530.

Poinot P., Arvisenet G., Ledauphin J., Gaillard J.-L., Prost C., 2013. How can aroma-related cross-modal interactions be analysed? A review of current methodologies. Food Qual. Pref., 28, 304-316.

Pomarici E., Lerro M., Chrysochou P., Vecchio R., Krystallis A., 2017. One size does (obviously not) fit all: Using product attributes for wine market segmentation. Wine Econ. Polic., 6 , 98-106.

Prescott J., Swain-Campbell N., 2000. Responses to repeated oral irritation by capsaicin, cinnamaldehyde and ethanol in PROP tasters and non-tasters. Chem. Senses, 25, 239-246.

Rinaldi A., Moio L., 2018. Effect of enological tannin addition on astringency subqualities and phenolic content of red wines. J. Sens. Stud., 33, e12325.

Robino A., Concas M.P., Spinelli S., Pierguidi L., Tepper B. J., Gasparini P., Prescott J., Monteleone E., Toschi, T.G.,Pagliarini E.,Gasperi F., Dinnella C., 2022. Combined influence of TAS2R38 genotype and PROP phenotype on the intensity of basic tastes, astringency and pungency in the italian taste project. Food Qual. Prefer., 95, 104361

Sáenz-Navajas M., Ferrero-del-Teso S., Jeffery D.W., Ferreira V., Fernández-Zurbano P., 2020. Effect of aroma perception on taste and mouthfeel dimensions of red wines: Correlation of sensory and chemical measurements. Food Res. Int., 131, 108945.

Sáenz-Navajas M., Campo E. Fernández-Zurbano P. Valentin D., Ferreira V., 2010. An assessment of the effects of wine volatiles on the perception of taste and adstringency in wine. Food Chem., 121, 1139-1149.

Santos-Buelga C., González-Manzano S., González-Paramás A.M., 2021. Wine, polyphenols, and mediterranean diets. what else is there to say? Molecules, 26, 5537.

Sereni A., Osborne J., Tomasino E., 2016. Exploring Retro-Nasal Aroma's Influence on Mouthfeel Perception of Chardonnay Wines. Beverages, 2, 7.

Singh N., Shaik F.A., Myal Y., Chelikani P., 2020. Chemosensory bitter taste receptors T2R4 and T2R14 activation attenuates proliferation and migration of breast cancer cells. Mol. Cell. Biochem, 465, 199-214.

Small D., 2012. Flavor is in the brain. Physiol. Behav., 107, 540-552.

Tepper B.J., 2008. Nutritional implications of genetic taste variation: The role of PROP sensitivity and other taste phenotypes Ann. Rev.Nutrit., 28, 367-388.

Tepper B.J., Christensen C.M., Cao J., 2001. Development of brief methods to classify individuals by PROP taster status. Physiol. Behav., 73, 571-577.

Wang Q.J., Mielby L.A., Junge J.Y., Bertelsen A.S., Kidmose U., Spence C., Byrne D.V., 2019. The Role of Intrinsic and Extrinsic Sensory Factors in Sweetness Perception of Food and Beverages: A Review. Foods, 8, 211.

Webb J., Bolhuis D., Cicerale S., Hayes J., Keast R., 2015. The relationships between common measurements of taste function. Chem. Percep., 8, 11-18.

Williams J., Bartoshuk L., Fillingim R., Dotson C., 2016. Exploring Ethnic Differences in Taste Perception. Chem. Senses, 41, 449-456. 